\title{
Development and Validation of Liquid Chromatography-Tandem Mass Spectrometry Method for Simultaneous Determination of Zinc Pyrithione and Pyrithione in Shampoos
}

\author{
T. H. Kim', G. H. Jung' ${ }^{2}$, E. H. Lee ${ }^{2}$, H. R. Park ${ }^{2}$, J. K. Lee ${ }^{2}$ and H. G. Kim²* \\ ${ }^{1}$ Bioresource Regional Innovation Center, Soonchunhyang University, Soonchunhyang-ro 22, \\ Shinchang-myun, Asan, Chungnam 31538, Republic of Korea \\ ${ }^{2}$ Department of Pharmacology, College of Medicine, Dankook University, Dandae-ro 119, \\ Dongnam-gu, Cheonan, Chungnam 31116, Republic of Korea
}

Received: 05 April 2017; accepted: 05 April 2017

\begin{abstract}
A simple, rapid, and sensitive liquid chromatography-tandem mass spectrometry (LC-MS/MS) method was developed and validated for the determination of zinc pyrithione ( $\mathrm{ZnPT})$ and pyrithione (PT) in shampoos. The method consisted of a liquid-liquid extraction for sample preparation. The mass spectrometer was operated in multiple reaction monitoring (MRM) mode via the positive electrospray ionization interface. A linear regression (weighted 1/x) was used to fit calibration curves over the concentration range of $50-2000 \mathrm{ng} / \mathrm{mL}$ for both ZnPT and PT. Excellent linearity $\left(r^{2} \geq 0.9996\right)$ was achieved for all. The method was validated and found to be accurate $(95.9-108.2 \%$ for $\mathrm{ZnPT}$ and $94.9-110.4 \%$ for PT), precise, and selective. Analytes in shampoos were found to be stable in the autosampler $\left(6^{\circ} \mathrm{C}\right.$ for $\left.6 \mathrm{~h}\right)$, in room temperature (for $6 \mathrm{~h}$ ), and after three freeze-thaw cycles, and recovery of analytes was reproducible (90.8-94.6\% for ZnPT and $90.2-96.3 \%$ for PT).
\end{abstract}

Keywords: Pyrithione, zinc pyrithione, LC-MS/MS, liquid-liquid extraction, shampoos

\section{Introduction}

Zinc pyrithione $(\mathrm{ZnPT})$ is a coordination complex of zinc with the chemical formula $\mathrm{C}_{10} \mathrm{H}_{8} \mathrm{~N}_{2} \mathrm{O}_{2} \mathrm{~S}_{2} \mathrm{Zn}$, resulting from combination of 2-mercaptopyridine-1-oxide with zinc (II) (Figure 1). It is also known as zinc pyridinethione, bis(2-pyridylthio) zinc, 2-mercaptopyridine $N$-oxide zinc salt, and under the commercial names of Danex, De-Squaman, Zinc Omadine, and Vancide ZP, which has been widely used as a bactericide, fungicide, algicide, and even an antidandruff agent. ZnPT can transform into copper pyrithione (CuPT) by transchelation with copper ion in the laboratory and under natural conditions $[1,2]$. The environmental toxicity of $\mathrm{ZnPT}$ or $\mathrm{CuPT}$ and their degradation products on microalgae, macrophytes, crustaceans, fish, sea urchin, and other organism have been studied [3-13]. ZnPT causes morphological abnormality in both killifish and zebrafish [5]. CuPT causes skeletal deformity in the fish Fundulus heteroclitus [9]. The toxicity of ZnPT after subchronic oral dosing has been studied in several animal species. Dogs dosed with ZnPT 6-12 mg/kg/day for 6 days show ocular lesions involving the tapetum lucidum $[14,15]$. Rats fed with a diet containing $250 \mathrm{ppm}$ ZnPT for 10 days showed locomotor abnormalities accompanied by muscle atrophy [16]. Rabbits dosed with $\mathrm{ZnPT} 17 \mathrm{mg} / \mathrm{kg} /$ day for 14 days developed hind-limb weakness that is associated with a dying-back neuropathy [17]

Based on its toxicity, ZnPT is allowed in a concentration of $1 \%$ for preservative purposes in cosmetic rinse-off hair care products and $2 \%$ for rinse-off antidandruff hair care products in the European Union (EU) [18]. Approximately 28\% of the shampoos in circulation on the market in 2013 have been reported to contain $\mathrm{ZnPT}$ and ethylenediaminetetraacetic acid (EDTA) together. EDTA will chelate the zinc from ZnPT and dissociate ZnPT into anion of pyrithione (Figure 2). This decomposition is speculated to increase the absorption of pyrithione anion and hence increase concerns about resulting

* Author for correspondence: hgkimm@dankook.ac.kr

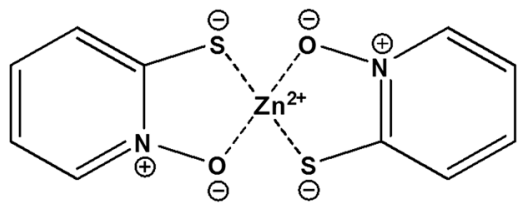

(A)<smiles>[O-][n+]1ccccc1S</smiles>

Figure 1. Structure of zinc pyrithione (A) and pyrithione (B)

toxicity. ZnPT has been reported to demonstrate low penetration, whereas sodium pyrithione (NaPT) with high water solubility was shown that it can be absorbed through skin in much greater amounts [19]. As a result, NaPT was designated as a prohibited ingredient in shampoo formulation. However, the current situation has been left without any criteria with respect to the formulation of $\mathrm{ZnPT}$ and EDTA.

There are many analytical methods for the determination of $\mathrm{ZnPT}$ in shampoos, environmental, and biological matrices [20-25]. However, chromatographic techniques for $\mathrm{ZnPT}$ and $\mathrm{PT}$ determination are rare, although the use of electrochemical techniques such as polarography, voltammetry, and amperometry have been investigated [26-30]. It has been analyzed by the way of radio-labeling, derivatization with fluorescing group, or transchelation to $\mathrm{Cu}$ (II) complex. However a direct, simple, and simultaneous analysis method for $\mathrm{ZnPT}$ and pyrithione (PT) is still lacking. Therefore, we attempted to develop and validate a sensitive and specific analytical method for the simultaneous determination of $\mathrm{ZnPT}$ and $\mathrm{PT}$ in shampoos using liquid chromatography-tandem mass spectrometry (LC-MS/MS).

\section{Experimental}

Chemicals and Reagents. Zinc pyrithione (ZnPT), pyrithione (PT), internal standard (IS), d $\mathrm{d}_{3}-5$-nitro-5'-hydroxyindirubin-3'-oxime $\left(\mathrm{d}_{3}-\mathrm{AGM}-130\right)$, ethylenediaminetetraacetic acid (EDTA), formic acid, and ammonium acetate were

This is an open-access article distributed under the terms of the Creative Commons Attribution-NonCommercial 4.0 International License (https://creativecommons.org/licenses/by-nc/4.0/), which permits unrestricted use, distribution, and reproduction in any medium for non-commercial purposes, provided the original author and source are credited, a link to the CC License is provided, and changes - if any - are indicated. 


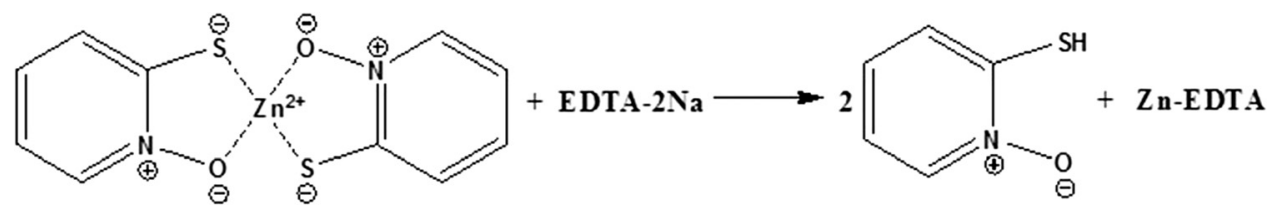

Figure 2. Reaction of $\mathrm{ZnPT}$ and EDTA

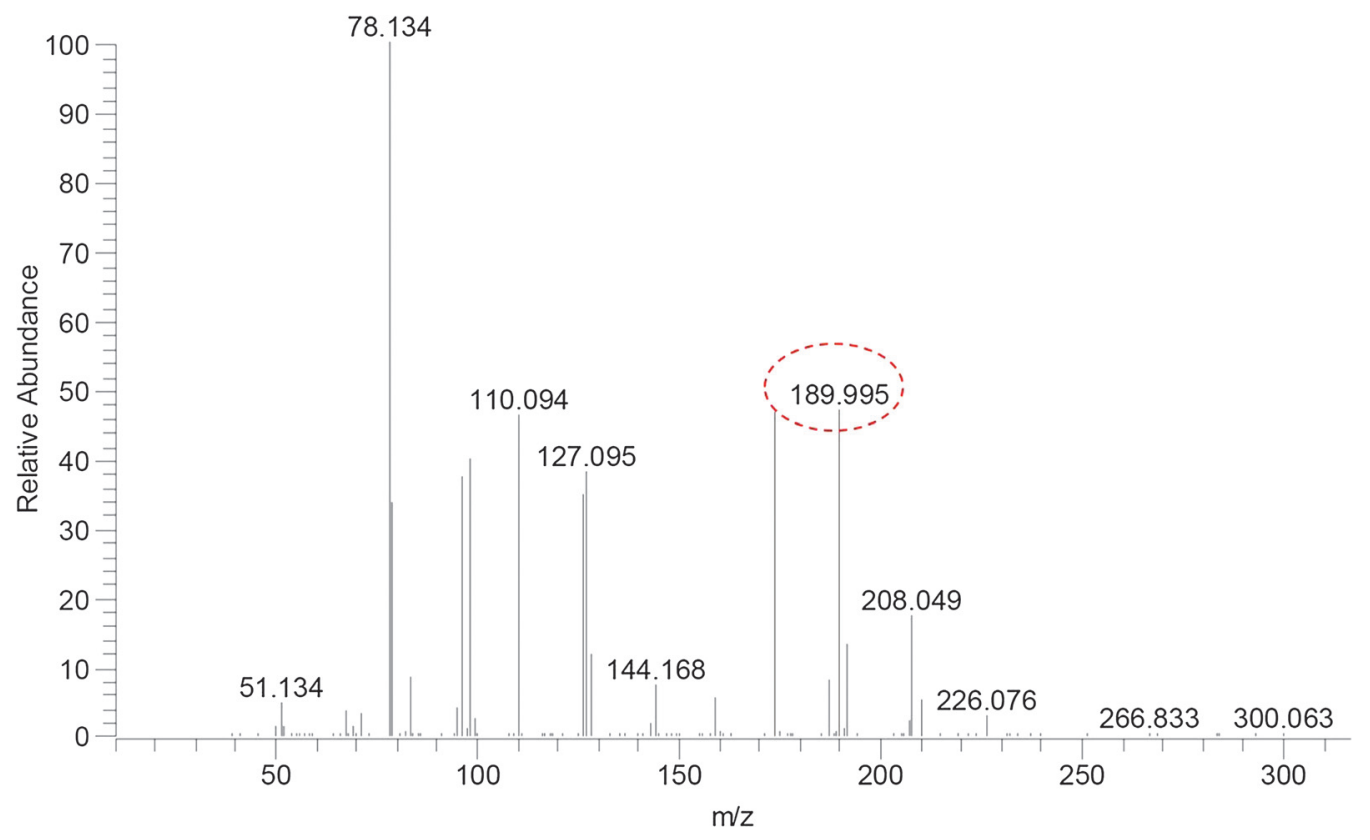

Figure 3. Product ion mass spectrum of $\mathrm{ZnPT}$

purchased from Sigma-Aldrich Chemical Corporation (St. Louis, MO, USA). Methanol (MeOH), chloroform, and water were purchased from Burdick and Jackson (Muskegon, MI, USA). All other chemicals and reagents were analytical grade and used without further purification.

Preparation of Shampoos, Standards, and Quality Control Samples. The shampoo formulations were prepared by adding $\mathrm{ZnPT}$ and EDTA in commercial shampoo product (Head \& Shoulder, USA) to yield a final concentration of 5\% ZnPT with and without $10 \%$ EDTA. The shampoo formulations were mixed thoroughly and then diluted 5 times with distilled water. The final diluted shampoo formulations (1\% ZnPT with and without 2\% EDTA) were used in experiments.

The stock solutions of ZnPT, PT, and IS ( $\mathrm{d}_{3}$-AGM-130) were prepared separately by dissolving them in chloroform- $\mathrm{MeOH}$ $(2: 1, \mathrm{v} / \mathrm{v})$ to yield a final concentration of $1 \mathrm{mg} / \mathrm{mL}$. The stock solutions were then diluted with methanol to yield standard working solutions of 50 to $2000 \mathrm{ng} / \mathrm{mL}$ for ZnPT and PT. A working solution of the IS was prepared by diluting IS stock solution with methanol to yield a final concentration of $5 \mu \mathrm{g} / \mathrm{mL}$.

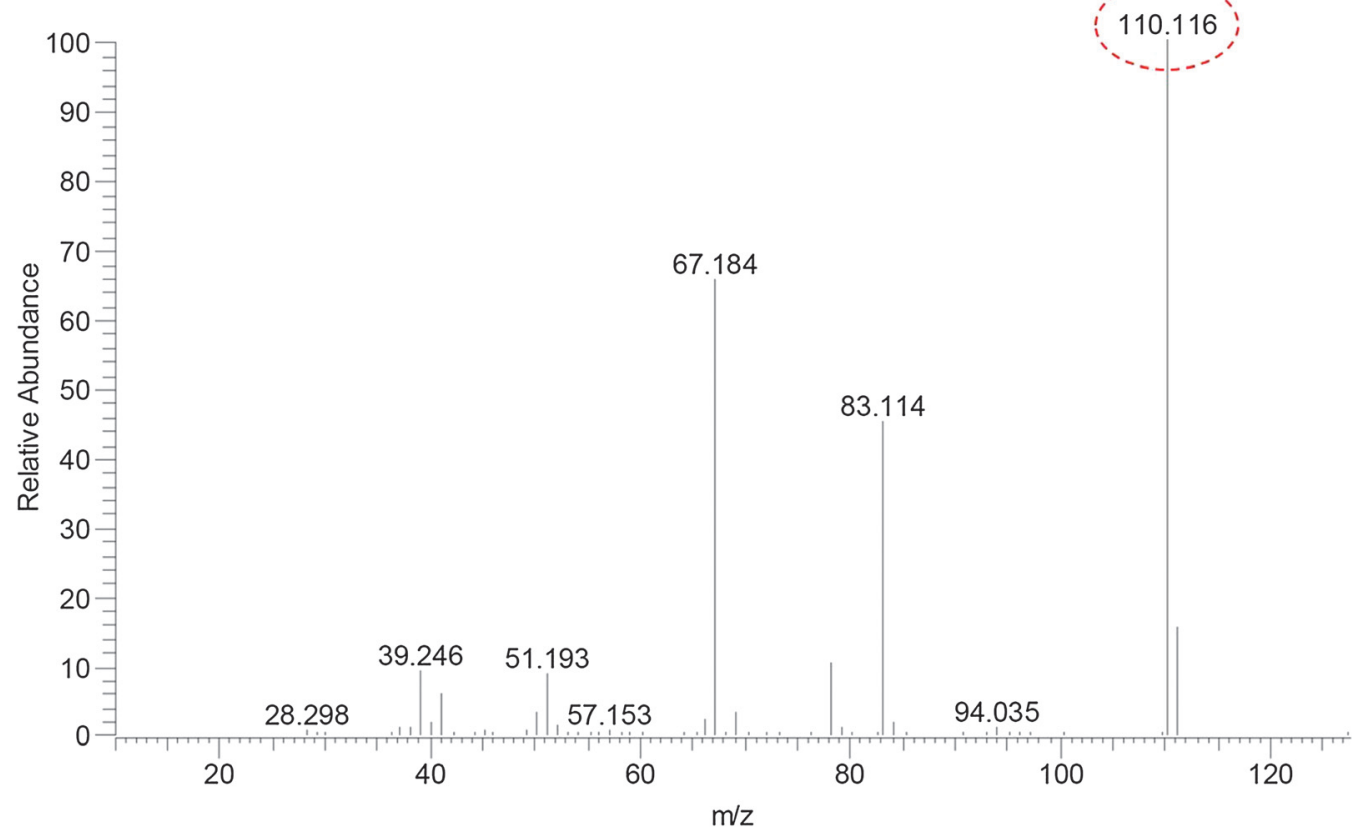

Figure 4. Product ion mass spectrum of PT 
Table 1. MS/MS conditions for zinc pyrithione ( $\mathrm{ZnPT}$ ), pyrithione (PT), and IS (d $\mathrm{d}_{3}$-AGM-130)

\begin{tabular}{lccc}
\hline Parameters & ZnPT & PT & IS $\left(\mathrm{d}_{3}-\mathrm{AGM}-130\right)$ \\
\hline Mass transition & $317 \rightarrow 190$ & $128 \rightarrow 110$ & $342 \rightarrow 279$ \\
Collision energy (ev) & 20 & 15 & 37 \\
Retention time (min) & 0.90 & 0.67 & 0.64 \\
Curtain gas (psi) & & 50 & \\
Collision gas (psi) & & 5 & \\
Source temperature $\left({ }^{\circ} \mathrm{C}\right)$ & & 400 & \\
\hline
\end{tabular}

These diluted working standard solutions were used to prepare the calibration curve and quality control (QC) samples.

Calibration standard and QC samples were prepared by spiking the blank shampoo with working solutions of each analyte to yield seven different concentrations over a range of $50-2000 \mathrm{ng} / \mathrm{mL}$ for $\mathrm{ZnPT}$ and PT. For QC samples, three concentration levels of standard samples $(100,500$, and $1600 \mathrm{ng} / \mathrm{mL})$ were prepared. All solutions were stored at $-20{ }^{\circ} \mathrm{C}$.

Sample Preparation. A volume of $5 \mu \mathrm{L}$ IS $(5 \mu \mathrm{g} / \mathrm{mL})$ and chloroform-MeOH $(2: 1, \mathrm{v} / \mathrm{v})(150 \mu \mathrm{L})$ were added to the calibration standards, QC, and shampoo samples $(50 \mu \mathrm{L})$, and

(A)

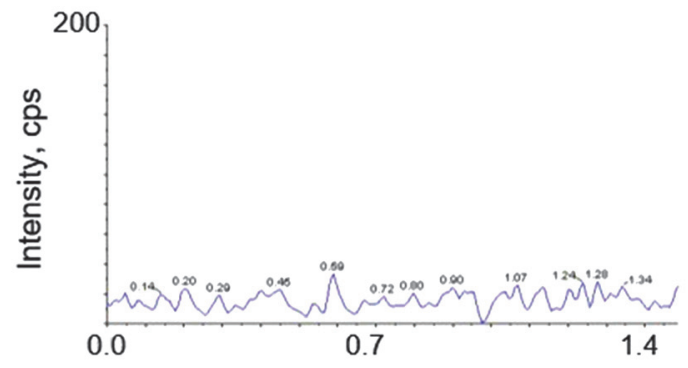

(B)

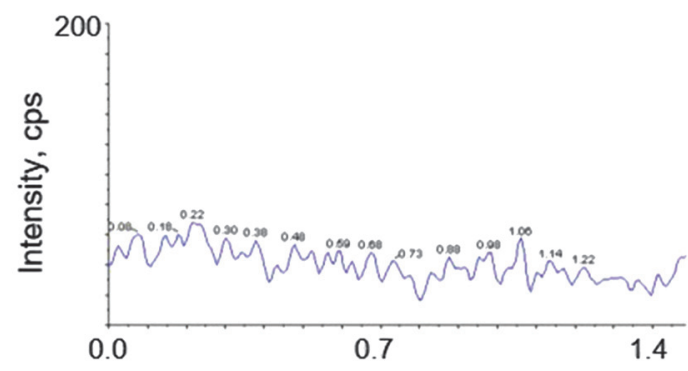

(C)
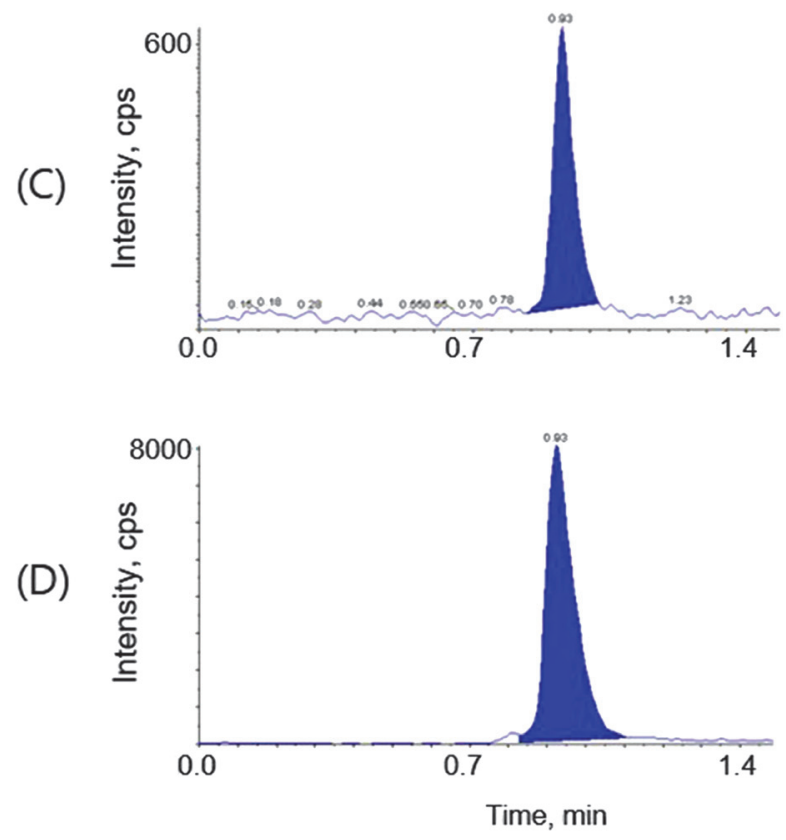

then the mixture were vortex-mixed for $1 \mathrm{~min}$. After centrifugation at $4{ }^{\circ} \mathrm{C}, 13,000 \mathrm{rpm}$ for $5 \mathrm{~min}$, the chloroform layers $(50 \mu \mathrm{L})$ were diluted with $\mathrm{MeOH}(50 \mu \mathrm{L})$. The processed samples $(5 \mu \mathrm{L})$ were analyzed by LC-MS/MS system.

Chromatographic Conditions. The liquid chromatographymass spectrometry system consisted of an Agilent 1290 series rapid resolution LC System and triple quadrupole linear ion trap mass spectrometer (4000 Q-Trap) (AB Sciex, Foster City, CA, USA). The analytical column used for this assay was a Gemini C18 column $(100 \times 3.0 \mathrm{~mm}, 3 \mu \mathrm{m}$, Phenomenex, Torrance, CA, USA) protected by a Security Guard column (4 mm $\times 3 \mathrm{~mm}$, Phenomenex, Torrance, CA, USA). The mobile phase consisted of deionized water with $20 \mathrm{mM}$ ammonium acetate and methanol with $0.1 \%$ formic acid $(10: 90, \mathrm{v} / \mathrm{v})$. The flow rate was set at $0.35 \mathrm{~mL} / \mathrm{min}$, and the injection volume was set at $5 \mu \mathrm{L}$.

The Q-Trap mass spectrometer was operated in the positive ion mode using an electrospray ionization source. High purity nitrogen gas was used for the nebulizer and curtain gases. The source temperature was set at $400{ }^{\circ} \mathrm{C}$ with a curtain gas flow of
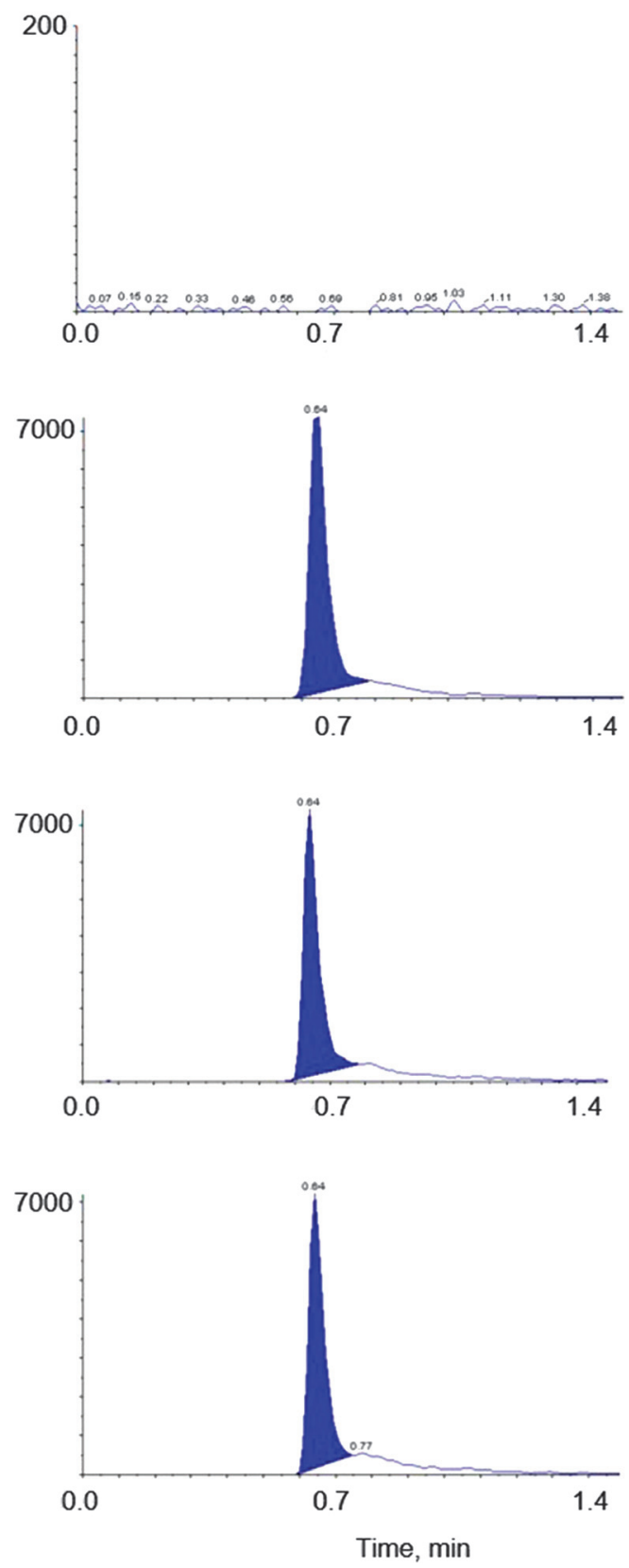

Figure 5. Representative chromatograms for $\mathrm{ZnPT}$ (left for $\mathrm{ZnPT}$; right for IS) at double blank (A), blank sample (B), LLOQ (50 ng/mL, C), and HLOQ (2000 ng/mL, D) in shampoo solution 
(A)
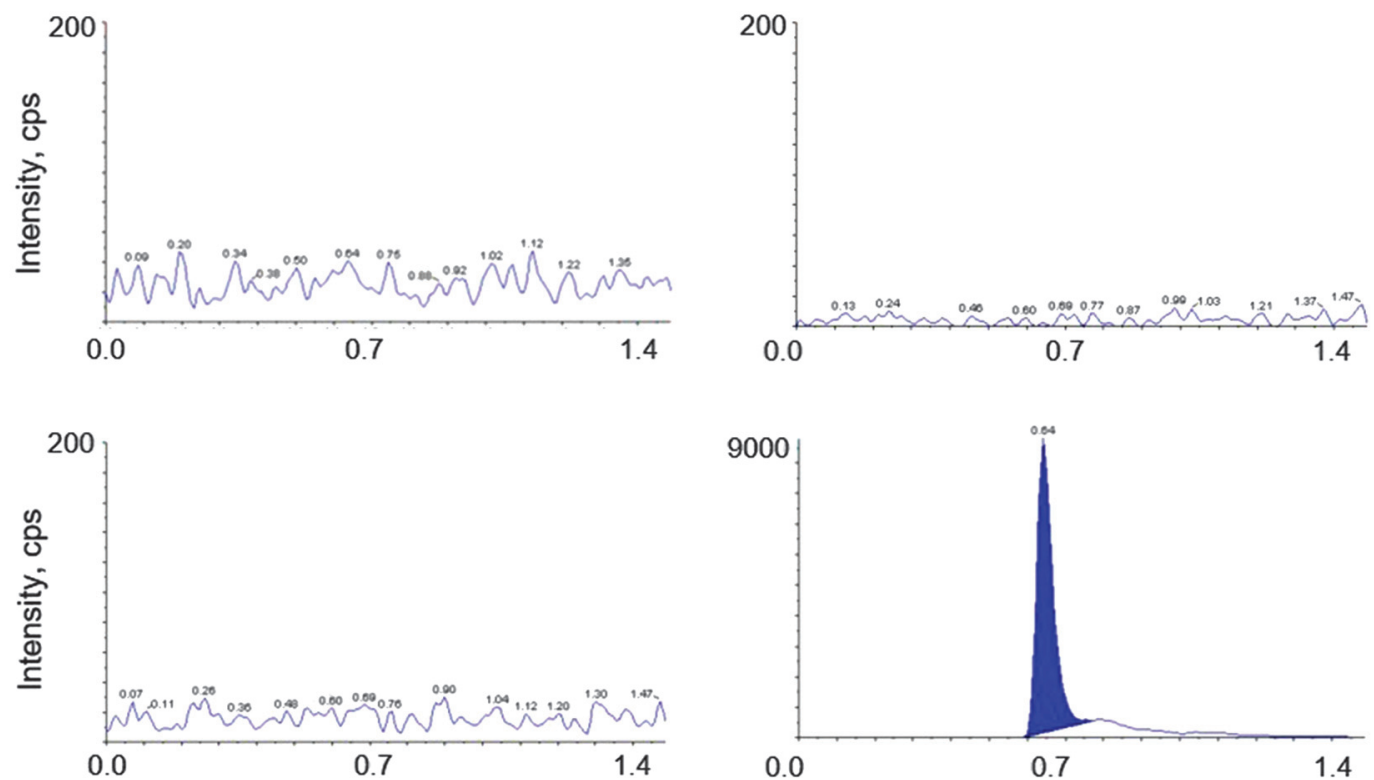

(C)
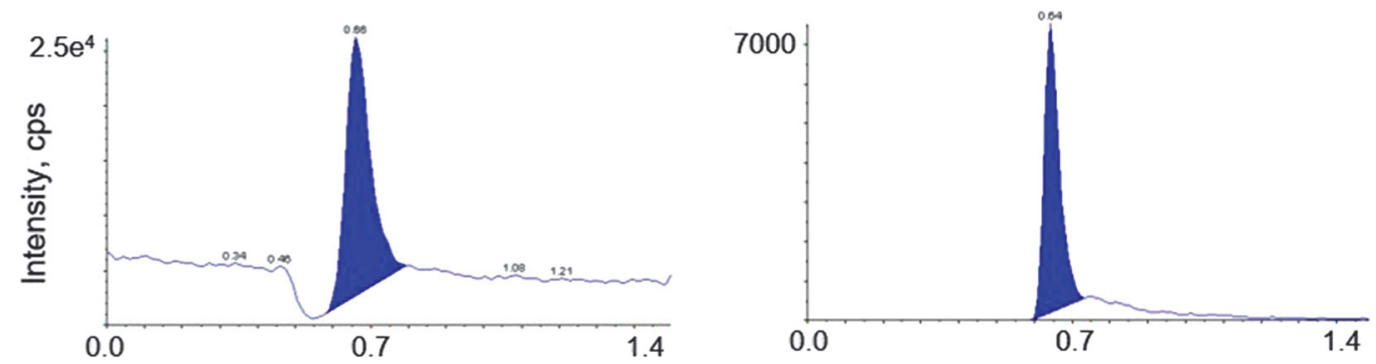

(D)
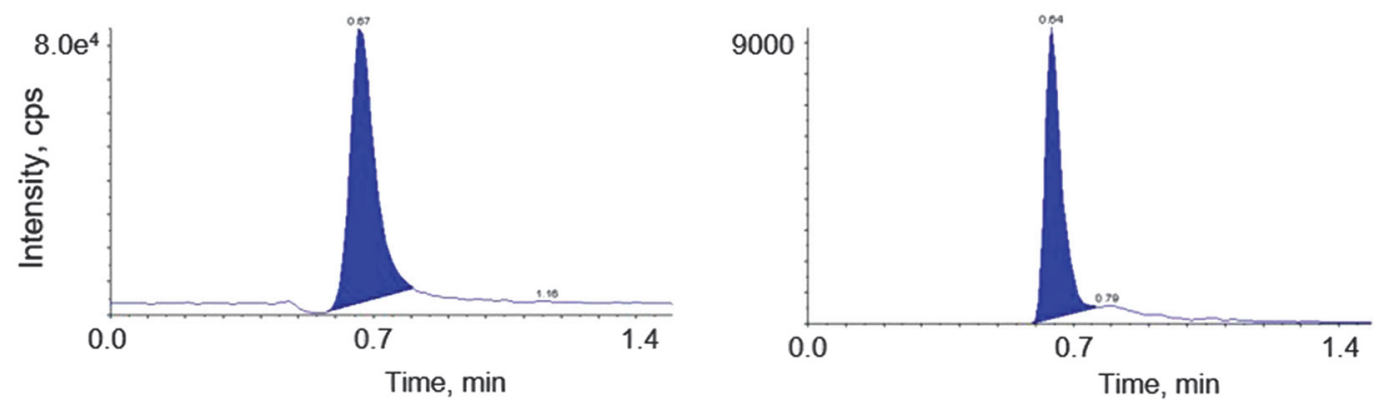

Figure 6. Representative chromatograms for PT (left for PT; right for IS) at double blank (A), blank sample (B), LLOQ (100 ng/mL, C), and HLOQ (2000 $\mathrm{ng} / \mathrm{mL}, \mathrm{D})$ in shampoo solution

$50 \mathrm{~L} / \mathrm{min}$. The ion spray voltage was set at $5500 \mathrm{~V}$, and the collision energy was 20 and $15 \mathrm{~V}$ for $\mathrm{ZnPT}$ and PT, respectively. The following multiple reaction monitoring (MRM) transitions of the respective $[\mathrm{M}+\mathrm{H}]^{+}$ions were used to quantify $\mathrm{ZnPT}$ and PT: ZnPT, $m / z 317 \rightarrow 190$; PT, $m / z 128 \rightarrow 110$; and $\mathrm{d}_{3}$-AGM-130 (IS), $\mathrm{m} / z 342 \rightarrow 279$. The dwell time for each transition was $150 \mathrm{~ms}$. Analyst software 1.6 was used to optimize the MS parameters, data acquisition, and data processing.

Validation and Sample Analysis Procedure. The validation was carried out according to the United States Food and Drug Administration (FDA) guidance for industry on bioanalytical method validation guidance [31]. Accuracy and precision were determined by quantification of the QC samples at four concentrations (LLOQ, low, mid, and high concentrations). Intra-day variability was determined by analyzing the QC samples three times using the same calibration curve. Interday variability was determined by analyzing the QC samples on three different days using calibration curves constructed on the respective days. Accuracy was calculated as the relative difference between calculated and nominal concentration of the QC samples (bias, \%), and precision was expressed as the relative standard deviation (RSD). The intra- and inter-day accuracy and precision should be within $\pm 15 \%$ except at LLOQ, which was set at within $\pm 20 \%$. The stability and recovery were evaluated at low, mid, and high concentrations ( $n=3$ at each concentration).

\section{Results and Discussion}

Liquid Chromatography-Tandem Mass Spectrometry Optimization. In this study, several conventional solvents such as methanol, acetonitrile, ethanol, and acetone were evaluated for method development. Even with $90 \%$ methanol, the peak appeared at the solvent front with tailing. Addition of $20 \mathrm{mM}$ ammonium acetate to the eluent was found to eliminate this problem. The best peak shape and retention time for $\mathrm{ZnPT}$ and PT were observed using methanol (containing $0.1 \%$ formic acid)/water (containing $20 \mathrm{mM}$ ammonium acetate) $(90: 10, \mathrm{v} / \mathrm{v})$ as the eluent. Chloroform, chloroform-methanol, ethyl acetate, and methyl-tert-butyl-ether were evaluated as 
extraction solvents for liquid-liquid extraction during method development. Among them, chloroform-methanol (2:1, v/v) was found to give the best extraction efficiency with less interference and faster sample preparation time.

The analytes were then separated on the $\mathrm{C} 18$ column within 2 min using isocratic elution. The collision energy and source temperature were carefully optimized for analytes and IS to produce the highest response in the detector. Product ion mass spectra of analytes are shown in Figures 3 and 4. Retention times, collision energy, gas pressure, and MRM transitions for the analytes and IS are shown in Table 1. All analytes formed protonated molecules of $[\mathrm{M}+\mathrm{H}]^{+}$when the mass spectrometer was operated under positive ionization mode. Dissociation was allowed to occur completely at $400{ }^{\circ} \mathrm{C}$, and quantification of ZnPT, PT, and IS was carried out using MRM of $m / z 317 \rightarrow 190,128 \rightarrow 110$, and $342 \rightarrow 279$, respectively.

Method Validation. Calibration curves were plotted based on the response ratio of analyte to internal standard versus the concentration of analyte. The calibration curve ranged from 50 to $2000 \mathrm{ng} / \mathrm{mL}$ for ZnPT and PT and exhibited excellent linearity with $r^{2}>0.9996$ using weighting of $1 / x$. Representative chromatograms of the calibration standards at the lower limits of quantitation (LLOQs) (signal-to-noise ratio, $>10$ ) are shown in Figures 5 and 6.

The intra- and inter-day accuracy as well as precision values of the method were assessed using spiked shampoo samples at concentrations of 50,100, 500, and $1600 \mathrm{ng} / \mathrm{mL}$ for $\mathrm{ZnPT}$ and PT. The intra- and inter-day accuracy values (\%) were in the range of $95.9-108.2 \%$ for $\mathrm{ZnPT}$ and $94.9-110.4 \%$ for PT. The intra- and inter-day precision values $(\mathrm{CV}, \%)$ were in the range of $1.8-10.5 \%$ for $\mathrm{ZnPT}$ and $0.8-13.9 \%$ for PT (Table 2). These data have met the requirement of the FDA guidance, and the developed method was shown to be accurate and reproducible in the simultaneous analysis of $\mathrm{ZnPT}$ and PT.

The developed method is specific and highly selective because no coeluting peaks were found in the drug-free shampoos (Figures 5 and 6). Recovery was determined by comparing the mean peak areas of low, mid, and high QC samples (processed) with the mean peak areas of extracted blank samples spiked with solution containing analyte and IS at concentrations representing $100 \%$ recovery (unprocessed). Recovery of $\mathrm{ZnPT}$ in the low, mid, and high QC samples was 93.9\%, 90.8\%, and 94.6\%, respectively, and recovery of PT was $93.4 \%, 90.2 \%$, and $96.3 \%$, respectively (Table 3 ). The results show that the liquidliquid extraction method is efficient.

Stability assessments were carried out to demonstrate that ZnPT and PT were stable under typical sample storage and processing conditions. The stability experiments for shampoos were performed using QC samples $(n=3)$ at the low, mid, and high QC levels. ZnPT and PT in shampoos were stable at room temperature for $6 \mathrm{~h}$, at autosampler tray $\left(4^{\circ} \mathrm{C}\right)$ for $6 \mathrm{~h}$, and through three freeze-thaw cycles (Table 4).

Table 2. Intra- and inter-day accuracy and precision of $\mathrm{ZnPT}$ and $\mathrm{PT}$ in LLOQ and QC samples

\begin{tabular}{|c|c|c|c|c|c|}
\hline & \multirow{2}{*}{$\begin{array}{l}\text { Concentration } \\
(\mathrm{ng} / \mathrm{mL})\end{array}$} & \multicolumn{2}{|c|}{ Intra-day $(n=3)$} & \multicolumn{2}{|c|}{ Inter-day $(n=3)$} \\
\hline & & $\begin{array}{l}\text { Accuracy } \\
\text { (bias, \%) }\end{array}$ & $\begin{array}{c}\text { Precision } \\
(\mathrm{CV}, \%)\end{array}$ & $\begin{array}{l}\text { Accuracy } \\
\text { (bias, \%) }\end{array}$ & $\begin{array}{c}\text { Precision } \\
(\mathrm{CV}, \%)\end{array}$ \\
\hline \multirow{4}{*}{$\mathrm{ZnPT}$} & 50 & 96.4 & 10.5 & 101.2 & 10.1 \\
\hline & 100 & 101.9 & 3.7 & 108.2 & 2.4 \\
\hline & 500 & 104.7 & 2.5 & 95.9 & 2.0 \\
\hline & 1600 & 103.4 & 2.3 & 106.3 & 1.8 \\
\hline \multirow{4}{*}{ PT } & 50 & 107.3 & 13.9 & 110.4 & 12.5 \\
\hline & 100 & 94.9 & 4.6 & 103.1 & 6.7 \\
\hline & 500 & 102.4 & 0.8 & 97.3 & 2.3 \\
\hline & 1600 & 107.6 & 3.4 & 105.5 & 1.4 \\
\hline
\end{tabular}

Table 3. Recovery of $\mathrm{ZnPT}$ and $\mathrm{PT}$ in QC samples

\begin{tabular}{lccr}
\hline & $\begin{array}{c}\text { QC samples } \\
(\mathrm{ng} / \mathrm{mL})\end{array}$ & Recovery $(n=3)$ \\
\cline { 3 - 4 } & 100 & 93.9 & $\mathrm{CV}(\%)$ \\
\hline \multirow{2}{*}{ ZnPT } & 500 & 90.8 & 12.0 \\
& 1600 & 94.6 & 4.3 \\
& 100 & 93.4 & 8.2 \\
PT & 500 & 90.2 & 13.3 \\
& 1600 & 96.3 & 4.1 \\
& & & 4.5 \\
\hline
\end{tabular}

Table 4. Stability of ZnPT and PT in QC samples $(n=3)$

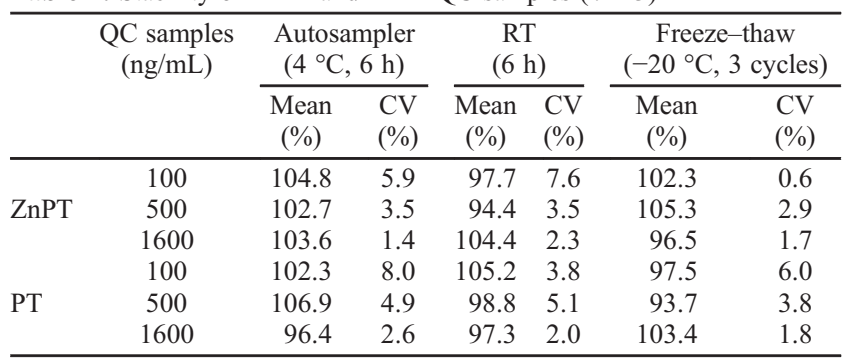

Table 5. Analysis results of $\mathrm{ZnPT}$ and $\mathrm{PT}$ in $1 \%$ of zinc pyrithione shampoo samples

\begin{tabular}{lcc}
\hline & Without EDTA & With EDTA \\
\hline ZnPT $(\mu \mathrm{g} / \mathrm{mL})$ & 9790 & 5820 \\
PT $(\mu \mathrm{g} / \mathrm{mL})$ & 1 & 1730 \\
\hline
\end{tabular}

Application of Methods. The validated LC-MS/MS method was successfully applied to the ZnPT shampoo samples with and without EDTA. The results are given in Table 5.

\section{Conclusions}

A rapid, precise, and accurate liquid chromatography-tandem mass spectrometry method was developed and validated for the simultaneous determination of $\mathrm{ZnPT}$ and $\mathrm{PT}$ in shampoos. The calibration curve showed goodness of fit over varying concentrations that ranged from 50 to $2000 \mathrm{ng} / \mathrm{mL}$ for $\mathrm{ZnPT}$ and PT. Intraand inter-day accuracy and precision for calibration standards and QC samples met the suggested industry and regulatory acceptance criteria. ZnPT and PT were stable in shampoos and extracts under the storage and test conditions used for this study. This liquid chromatography tandem-mass spectrometry method is very sensitive, selective, accurate, and reproducible for the determination of ZnPT and PT concentration in shampoos.

The simultaneous assay of ZnPT and PT from the ZnPT shampoos with and without EDTA has been applied successfully for the formulation analysis. There might be increased risk of absorbed PT toxicity of ZnPT containing shampoo by the addition of EDTA due to partial dissociation of ZnPT into PT. Therefore, this developed method should be adopted for the potential risk assessment of dissociated PT from the ZnPT and EDTA containing shampoos.

Acknowledgment. This work was supported by a grant (14172MFDS975) from the Ministry of Food and Drug Safety, Korea in 2014.

\footnotetext{
References

1. Grunnet, K. S.; Dahllof, I. Environ. Toxicol. Chem. 2005, 24, 3001.

2. Thoma, K. V. J. Chromatogr. A 1999, 833, 105.

3. Bao, V. W. W.; Leung, K. M. Y.; Kwok, K. W. H.; Zhang, A. Q.; Lui, G. C. S. Mar. Pollut. Bull. 2008, 57, 616.

4. Bellas, J.; Granmo, A.; Beiras, R. Mar. Pollut. Bull. 2005, 50, 1382.

5. Goka, K. Environ. Res. 1999, 81, 81.

6. Kobayashi, N.; Okamura, H. Mar. Pollut. Bull. 2002, 44, 748.
} 
7. Koutsaftis, A.; Aoyama, I. Environ. Toxicol. 2006, 21, 432.

8. Mochida, K.; Ito, K.; Harino, H.; Kakuno, A.; Fujii, K. Environ. Toxicol. Chem. 2006, 25, 3058 .

9. Mochida, K.; Ito, K.; Harino, H.; Onduka, T.; Kakuno, A.; Fujii, K. Environ. Toxicol. Chem. 2008, 27, 367.

10. Mochida, K.; Ito, K.; Harino, H.; Tanaka, H.; Onduka, T.; Kakuno, A.; Fujii, K. Comp. Biochem. Physiol. C 2009, 149, 624.

11. Mochida, K.; Amano, H.; Onduka, T.; Kakuno, A.; Fujii, K. Chemosphere 2011, 82, 390.

12. Onduka, T.; Mochida, K.; Harino, H.; Ito, K.; Kakuno, A.; Fujii, K. Arch. Environ. Contam. Toxicol. 2010, 58, 991.

13. Okamura, H.; Watanabe, T.; Aoyama, I.; Hasobe, M. Chemosphere 2002, 46, 945.

14. Cloyd, G. G.; Wyman, M.; Shadduck, J. A.; Winrow, M. J.; Johnson, G. R. Toxicol. Appl. Pharmacol. 1978, 45, 771.

15. Snyder, F. H.; Buehler, E. V.; Winek, C. L. Toxicol. Appl. Pharmacol. 1965, 7, 425 .

16. Snyder, D. R.; Gralla, E. J.; Coleman, G. L. Food Cosmet. Toxicol. 1977, $15,43$.

17. Sahenk, Z.; Mendell, J. R. Neurology 1977, 27, 393.

18. Scientific Committee on Consumer Safety (SCCS) Opinion on Zinc Pyrithione (Colipa P81) 2014.

19. Howes, D.; Black, J. G. Toxicol. 1975, 5, 209.
20. Gibson, W. B.; Jeffcoat, A. R.; Turan, T. S.; Wendt, R. H.; Hughes, P. F.; Twine, M. E. Toxicol. Appl. Pharmacol. 1982, 62, 237.

21. Kabacoff, B. L.; Fairchild, C. M. J. Soc. Cosmet. Chem. 1975, 26, 453.

22. Voulvoulis, N.; Scrimshaw, M. D.; Lester, J. N. Chemosphere 1999, 38, 3503.

23. Yamaguchi, Y.; Kumakura, A.; Sugasawa, S.; Harino, H.; Yamada, Y.; Shibata, K.; Senda, T. Int. J. Environ. Anal. Chem. 2006, 86, 83.

24. Gu, Y. X.; Wang, Q. H.; Zhou, Z. L.; Lv, Q.; Mai, C. H. J. Cosmet. Sci. 2014, 65, 265

25. Chen, G.; Miao, M.; Hoptroff, M.; Fei, X.; Collins, L. Z.; Jones, A.; Janssen, H. G. J. Chromatogr. B 2015, 1003, 22.

26. Krivis, A. F.; Gazda, E. S.; Supp, G. R.; Robinson, M. A. Anal. Chem. $1963,35,966$

27. Wang, L. H. Electroanalysis 2000, 12, 227.

28. Mackie, D. S.; van den Berg, C. M. G.; Readman, J. W. Anal. Chim. Acta. 2004, 511, 47.

29. Montoya, M. R.; Galvin, R. M.; Mellado, J. M. R. Electroanalysis $1998,10,1030$

30. Shih, Y.; Zen, J. M.; Kumar, A. S.; Chen, P. Y. Talanta 2004, 62, 912.

31. Guidance for Industry, Bioanalytical Method Validation, US Department of Health and Human Services, Food and Drug Administration, Center for Drug Evaluation and Research (CDER), Center for Veterinary Medicine (CVM) May 2001. 